\title{
Sports and Humanitarian Development: A Look at Sports Programming in the Refugee Crisis Through a Case Study of KickStart Joy Soccer Project at the Zaatari Refugee Camp
}

\author{
Elizabeth Cheung-Gaffney*
}

\begin{abstract}
The international development community is increasingly looking toward sports programs to play a role in the development of marginalized populations in both disaster and developing contexts. All aspects of the aid community, including governments, non-governmental organizations (NGOs), and civil society, increasingly look toward the growing body of international treatises as a framework to maximize the role that sports programming can play in the lives of marginalized youth. This case study of a soccer program in Zaatari Refugee Camp highlights how the different parts of this movement come together, particularly the international treatises, legal regulations, and public/private partnerships.
\end{abstract}

\section{Introduction}

Their exact numbers and whereabouts are unknown. ${ }^{1}$ The amount of aid they receive is also unknown. ${ }^{2}$ The world cannot even agree on a standard definition identifying them as a distinct group in need. ${ }^{3}$ As a result, it comes as no surprise that refugee youth have been called "invisible" by the United Nations Refugee

\footnotetext{
1 We Believe In Youth, Global Refugee Youth Consultations Final Report September 2016, Women's Refugee Commission, UNHCR. "Most humanitarian organizations, including [UNHCR], have limited data on Refugee Youth (aged 15-24), so reliable statistics on the actual number of Refugee Youth globally are not available."

2 Investing in Children and Youth, UNICEF Office of the Secretary-General Envoy on Youth (2016) at p. 5, ("As with domestic public finance, existing [overseas development aid] classifications do not permit tracking the full amount of aid that addresses the needs of children and youth (for example there is no child or youth-focused equivalent to the [overseas development aid] gender-equality marker."

3 UNHCR Policy Development and Evaluation Service Report: "UNHCR lacks an official definition of youth."
}

* Elizabeth Cheung-Gaffney, JD, is a legal counsel and senior program officer at The Catalyst Foundation; email: ecgaffney@thecatalystfdn.org 
Agency (UNHCR). ${ }^{4}$ While there is no specific data that is collected for this group, organizations have estimated that of the 21.3 million refugees worldwide or in exile, more than half are under the age of $18 .{ }^{5}$ If we change the age group from under 18 to include ages $15-24,{ }^{6}$ some estimates put the total number of migrant youth at 28.2 million.

What the world does know is how vulnerable they are. Despite international law guaranteeing youth under 18 the right to an education, ${ }^{8}$ according to UNHCR only half of elementary age refugee youth are in school, and the percentage enrolled in secondary education drops to $22 \% .{ }^{9}$ The numbers are so low because the obstacles to accessing education are so high. The obstacles most commonly cited are the cost of education and transportation, child labor, and child marriage. ${ }^{10} \mathrm{On}$ top of these most commonly cited barriers, refugee youth are confronted with overcrowded classrooms, curriculum difficulties, availability of schools, and local schools denying enrollment. ${ }^{11}$

As a result, the choices for many refugee youth and their parents are stark: The obstacles to getting into formal education seem insurmountable but the alternative is to become prey to child labor or child marriage. It is into this void that local and international organizations create programs that target refugee youth that act as a "stopgap" measure while families figure out how to get their children back into formal education. ${ }^{12}$ But given how little attention has been paid to this marginalized group up until recently, it comes as no surprise that refugee youth programming can at best be described as "ad hoc" and often subject to the whims of in-country interest and funding. ${ }^{13}$

\section{Sport for Development}

This ad hoc approach is slowly changing, particularly in sports programming. To date, sports programs in humanitarian situations have been isolated and informal

\footnotetext{
4 http://www.unhcr.org/513f37bb9.pdf, UNHCR's Engagement with Displaced Youth at 15.

http://unfoundationblog.org/4-facts-to-know-about-the-global-refugee-crisis/

6 Global Migration Group: Migration and Youth Report, 2014. See also Youth Issue Briefs 2016, UN Department of Economic and Social Affairs. The UN defines youth as those aged 15-24, but this distinction is mainly for statistical purposes.

7 Id.

81989 Convention on the Rights of Children and 1951 Refugee Convention. See also UNHCR, 2016 Missing Out: Refugee Education in Crisis, http://www.unhcr.org/en-us/missing-out-state-ofeducation-for-the-worlds-refugees.html.

9 http://www.unhcr.org/afr/news/press/2016/9/57d7d6f34/unhcr-reports-crisis-refugee-education.html. This statistic is compared to a global average of $84 \%$ attending secondary.

10 Right to Play internal memorandum, available upon request.

11 Id.

12 Id.

13 Id. See also Progress in the implementation of commitment to children and youth under the Addis Ababa Financing for Development Agenda, at 3 ("For social protection, specific child and family benefit programmes rooted in legislation exist in 108 countries. Yet, these programs often cover only small groups of the population.")
} 
and have "yet to be mainstreamed into the development agenda" of international aid. ${ }^{14}$ The emerging field of sport for development ${ }^{15}$ is trying to change that by using sport in a coordinated and strategic way. The area of sport for development takes the disparate actors that work in this space: the humanitarian organizations, governments, United Nations (UN) agencies, as well as the corporate social responsibility practices, private individuals, and civil society, and seeks to develop common frameworks and definitions for action across different sectors in order to move the field to be more effective and impactful.

The importance of sport is not a new concept; in fact, it is often accepted as a universal "human right" and has even been acknowledged as the "forgotten right." 16 There are signs that the international aid community, governmental organizations, and civil society are looking for ways to obtain recognition for this "forgotten right." They are interested in sports as a tool for addressing some of the challenges that arise from humanitarian crises and in conflict and post-conflict settings. There has been much written about the benefits of sport, particularly that " $[\mathrm{t}] \mathrm{h}$ life skills learned through sport help empower individuals and enhance psycho-social well-being, such as increased resiliency, self-esteem, and connections with others." 17

Arguably, refugee youth need these skills more than any other group. They live in densely populated and tight spaces that do not allow for spontaneous free play and physical activity, which is necessary to combat social and psychological problems. Moreover, free play spaces and structured sports programs are especially important for girls due to "increased pressure from conservative sectors" of society that restrict girls' access to spontaneous play. ${ }^{18}$ Structured sports programming as a component of development aid provided at community centers sometimes offer the only opportunity for refugee youth to participate in physical activity. ${ }^{19}$

This article will provide a brief overview of the broader body of international refugee law and how this body of law addresses the right to sport question,

\footnotetext{
14 https://www.un.org/sport2005/resources/task_force.pdf

$15 \mathrm{See}$ http://www.sportanddev.org for a comprehensive look at the sport and development movement.

16 Unicef's Convention on the Rights of the Child Implementation manual (1999) notes that: "Children's right to play is sometimes referred to as the 'forgotten right.' Perhaps because to it appears to the adult world as a luxury rather than a necessity of life."

${ }^{17}$ https://www.un.org/sport2005/resources/task_force.pdf. See also The International Play Association: Promoting the Child's Right to Play (2016) ("Play is a critical and intrinsic part of healthy human life and development and a child's ability to exercise the right to play should not be dependent on the environmental conditions where that child lives or the family they were born into.").

18 Smart Interactive Classrooms in the Gaza Strip, Right to Play (2018) (These problems are magnified for girls under the age of 15 , as increased pressure from conservative sectors of society in Gaza has less and less opportunities for girls compared to boys. Increasingly, girls are banned from engaging in play and physical activities in open spaces, which includes school playgrounds. The dominant social structures and religious traditions continue to restrict girls' access to open spaces for play, and technology for learning."”).
}

19 Id. 
followed by a more granular look at the procedures and legal issues of entering a refugee camp as a programming provider. Finally, a description of the KickStart Joy soccer program at the Zaatari Refugee Camp in Jordan will bring into focus all the parts of the refugee crisis and sport for development. We will see how the body of legal conventions and charters lay the groundwork for sport for development's backbone - the collaboration between international sporting organizations, the private sector, and civil society. KickStart Joy shows how these partnerships embody the core beliefs of both refugee law and sport for development at the same time as navigating the country-level tensions between security and humanitarian aid.

\section{Overview of the Legal Status of Refugees}

Refugees are defined as people who are fleeing conflict or persecution. ${ }^{20}$ Officially, according to the UNHCR, which is the world body's chief refugee services organization under the auspices of the UN, a refugee is defined as any person who,

[O]wing to well-founded fear of being persecuted for reasons of race, religion, nationality, membership of a particular social group, or political opinion, is outside the country of his nationality and is unable or, owing to such fear, is unwilling to avail himself of the protection of that country; or who, not having a nationality and being outside the country of his former habitual residence, is unable or owing to such fear, is unwilling to return to it. ${ }^{21}$

The core mandate is to protect and find durable solutions for refugees and other "persons of concerns." 22

Accomplishing this mandate has presented many challenges and resulted in varying systems towards "protecting" and finding "durable solutions" for refugees. The post-World War II focused 1951 Refugee Convention gives refugees rights and obligations that are dependent on a host state; however, the UNHCR soon realized the difficulty involved in pressuring host states to provide for the welfare of refugees that do not have the resources or capacity to fulfill these obligations. Instead, the UNHCR settled on an "assistance" approach in which

\footnotetext{
201951 Convention relating to the Status of Refugees and the 1967 Protocol. UNHCR, Convention and Protocol Relating to the Status of Refugees, U.N.G.A. 2198 (XXI) (1951). See, generally, UNHCR, The 1951 Convention relating to the Status of Refugees and its 1967 Protocol (2011) (since the Convention was limited to refugees fleeing events in Europe prior to 1951, the Protocol was passed to obligate parties to comply with the substantive provisions of the 1951 Convention without geographic or temporal limitation).

21 Id.

22 "Persons of concern" is a UNHCR category that includes refugees or persons in refugee-like situations, internally displaced persons and returnees, asylum-seekers, stateless persons, and other "persons-of-concern."
} 
it offered "independent social services, infrastructure, migration programs and even security forces." 23

This parallel system model was the creation of the "refugee camp" where the camps are the primary means of administering sanctuary to large-scale refugee crisis. Hence, the UNHCR "often acts as a surrogate state administering social services, migration programs, or infrastructure in camps." ${ }^{24}$ It is in the refugee camps that UNHCR takes on the responsibility of ensuring that the basic rights of refugees guaranteed by international law are met.

International refugee law, which is a patchwork of international treaties, individual country laws, and bilateral agreements, guarantees refugees numerous rights - among them are the free exercise of religion, access to education, and a right to work. ${ }^{25}$

Although the Refugee Convention does not include the right to sport, there are many international conventions and charters that recognize the stark reality of refugees, particularly refugee youth, and address the access and right to sport. However, like most public international law doctrine, the conventions and charters have limited direct enforceability. As a result, advocates have cited these agreements to lend both the weight of accepted international law and moral authority to their causes. Thus, advocates of various causes have used international conventions to gain legal recognition of many rights including, but not limited to, the right to an identity, ${ }^{26}$ a recognition of inheritance rights, and a right to know your paternity. ${ }^{27}$

As previously noted, though the legal right to sport has not yet been recognized, it is worth exploring the various conventions and charters with regard to the right to sport to identify how international norms view a refugee's right to sport.

\section{International Charters and Conventions}

The International guidelines provide the basic recommendations for the mix of actors that operate in the sport for development space. At the core of these guidelines is the bold belief that "[s]port is far more than a luxury or form of entertainment. Access to and participation in sport is a human right and essential for individuals of all ages to lead healthy and fulfilling lives." 28 This principle is a common thread that runs through each of the legal instruments that make up the body of international refugee law and are a valuable source of authority to underpin the strategic planning and development of sports programming for refugee youth.

\footnotetext{
23 What Happens to Law In a Refugee Camp? Elizabeth Holzer, 47 Law. \& Soc'y Rev. 837, at 846.

24 Id. at 843.

25 See 1951 United Nations Convention Relating to the Status of Refugees, Article 12-30 for an exhaustive list.

26 Contreras et al. v. El Salvado, Inter-Am. Ct. H.R. (ser. C) No. 232 (Aug. 31, 2011).

27 Atala Riffo and Daughters, (ser. C) No. 239 at P 109.

28 Sport as a Tool for Development, at 5 (emphasis added), https://www.un.org/sport2005/resources/task_force.pdf
} 


\section{International Convention on the Rights of the Child, Article 31}

The law regarding children's rights became codified in 1989 by the General Assembly of the UN when The Convention on the Rights of the Child (CRC) was unanimously approved by the General Assembly and was the fastest international treaty to reach the required number of ratifications. ${ }^{29}$ The CRC sets out the civil, political, social, health, and cultural rights of children in 54 articles, including three optional protocols.

Significantly, Article 31 of the CRC provides that "every child has the right to rest and leisure, to engage in play and recreational activities appropriate to the age of the child and to participate freely in cultural life and the arts." The same puts an obligation on member governments "to respect and promote the right of the child to participate fully in cultural and artistic life, ... encourage the provision of appropriate and equal opportunities for cultural, artistic, recreational and leisure activity."

Moreover, Article 2(1) of the CRC obliges member states to guarantee the rights enshrined in the Convention to each child within their jurisdiction without discrimination of any kind, including national origin. As such, refugee children have a right to engage in play and recreation while their host governments have a duty to promote the refugee youth's participation in sports activities.

While the ratification of the CRC was swift, recognition and enforcement of these rights has proven more difficult. The third optional protocol of the CRC was adopted in 2003, which created a Committee on the Rights of the Child and went into effect in 2014. This Committee created an international complaints procedure for violations of child rights directly to the Committee.

Many critics of the CRC have noted that due to a lack of enforcement mechanisms, the CRC's effectiveness is limited. This argument ignores the recent advances. Individual countries have adopted legal instruments and/or policies into their legislative frameworks that can be seen as institutionalizing the "right to sport." "For example, civil society organizations in the United States all follow the "Bill of Rights for Young Athletes" recognizing the relationship between sports and human rights. ${ }^{31}$ South Africa has gone even further by including in its Bill of Rights, the right of every child to "basic nutrition, shelter, basic health care and social services." "Social services" has been suggested to include sport and recreation. ${ }^{32}$ In Australia, it has been argued that the county's Disability Discrimination Act 1992 indirectly suggests that all members of the community have the right to enjoy and access sport.

\footnotetext{
29 See Human Rights Watch Report on the $25^{\text {th }}$ Anniversary of the Convention on the Rights of the Child, "The Convention on the Rights of the Child is the most rapidly and widely ratified human rights treaty in history — with 194 countries as 'states parties."” Report available from the author.

30 Ireland-Piper, Is There a 'Right' to Sport, Bond University Sports Law EJournal (2014).

31 See Bill of Rights for Young Athletes, Vern Seefold \& Rainer Mortens. American Alliance for Health and Physcial Education, Recreations and Dance (1979).

32 See Ireland, citing Mira Dutschke, Defining Children's Rights to Social Services.
} 


\section{Sports as a Means to Promote Education, Health, Development, and Peace: UN General Assembly Resultion A/RES/58/5 33}

The UN General Assembly adopted Resolution 58/5, titled "Sports As a Means to Promote Education, Health, Development and Peace" in November 2003. This resolution and the initiatives surrounding it represent the UN's recognition that sport-based programs are a natural partnership for the UN system, and that sport is a tool that should be used to reach the Millennium Development Goals.

Specifically, the resolution designated 2005 the International Year of the Sport and Physical Education. The resolution further notes "with concern the dangers faced by ... young athletes, including, inter alia, child labour, violence, [...] as well as less visible threats and deprivations, such as the premature severance of family bonds and the loss of sporting, social and cultural ties." ${ }^{34}$

For refugee youth in particular, these "less visible threats" are facts of life. This resolution encourages "international sports bodies and sport-related organizations to elaborate and implement partnership initiatives and development projects." 35

The UN recognizes the importance of sport, but more importantly, the UN stresses the need for "strategic partnerships" between international sporting bodies, sports organizations, and the private sector as a way to ensure that "young talents can develop their athletic potential without any threat to their safety and physical and moral integrity." ${ }^{36}$

Given how thinly stretched governments and public organizations are in the current refugee crises around the world, it is only through private partnerships that the gaps for sports programming can be filled.

\section{UNESCO's International Charter of Physical Education and Sport $^{37}$}

Article 1 of the United Nations Educational, Scientific and Cultural Organization's (UNESCO) International Charter of Physical Education and Sport provides that the "practice of physical education, physical activity and sport is a fundamental right for all." This Charter was adopted on November 21, 1978, and makes sport a right for all, but goes further to establish sport as an essential element of an education system. Updated in 2015, this charter sought to push the right to sport further by renewing the commitment of the international sports community to actively promote sport as a catalyst for peace and development.

The Charter recognizes that sport and physical education can be a force for human progress and identifies international cooperation as a prerequisite for the

\footnotetext{
33 Resolution 58/5 Adopted by the UN General Assembly, Fifty-Eighth Session, Plenary Meetings, November 17, 2003.

34 Id.

35 Id.

36 Id.

37 Adopted by the General Conference at its 20th session, Paris, November 21, 1978.
} 
use of physical education and sport. It calls for the development of research and exchange of documentation and information about physical education and sport.

\section{Regional Charters Addressing the Access to Sport}

Other than the international UN-related charters and conventions, there have been a few regional conventions that are instructive on using sport for development. First, the American Convention of Human Rights ${ }^{38}$ was passed in November 1969 and provides a helpful framework for countries in the Western hemisphere to outline a basic framework of "personal liberty and social justice based on respect for the essential rights of man." 39 Article 16 of the convention provides "[e]veryone has the right to associate freely for ideological, religious, political, economic, labor, social, cultural, sports, or other purposes." 40 The oversight body for this convention is the Inter-American Commission on Human Rights and the Inter-American Court for Human Rights. This is critical since the InterAmerican Court for Human Rights has been a successful forum for many cases, establishing rights for youth under the Children's Convention.

The European Sport for All Charter is another regional document that seeks to outline common principles for a region. In this case, the European countries have signed onto a framework that provides outlines for sports policy towards all participants, guaranteeing access to all sports facilities or sports activities (see Article 4(1)). ${ }^{41}$

\section{A Comparative Look at Parallel Developments in International Recognition of Marginalized Groups in Sports}

As previously noted, the international conventions and charters provide only guidelines and frameworks for the emerging field of sport for development and the right to sport. Therefore, it is instructive to look at other developments in the "right to sport" space, specifically the discrimination and Olympic space, as examples and lessons on using these humanitarian instruments. Taken together, it will show that there are areas of sport where the courts and international community have recognized the intrinsic right to access sport.

\section{Through the Lens of Discrimination Against Disabilities}

One area that might prove instructive to support the argument for the right to play sports is to look at this issue through the discrimination lens. Refugees enjoy the

\footnotetext{
38 American Convention on Human Rights, signed at the Inter-American Specialized Conference on Human Rights, San Josi, Costa Rica, November 22, 1969.

39 Id. at Preamble.

40 Id. at Chapter 2, article 16.

41 European Sports Charter, Article 4, adopted by the Committee of Ministers on September 24, 1992, at the 480th meeting of the Ministers' Deputies and revised at their 752nd meeting on May $16,2001$.
} 
negative right not to be prohibited from joining recreational/sports associations. Article 15 of the 1951 Refugee Convention requires state parties to protect the "rights of refugees to form or join already existing trade unions, and associations with cultural, sports, social, or philanthropic mandates." 42

The right not to be discriminated against in joining sports associations is also recognized by Article 16 of the American Convention of Human Rights, which establishes that "[e]veryone has the right to associate freely for ideological, religious, political, economic, labor, social, cultural, sports, or other purposes." 43 The International Convention on the Rights of Persons with Disabilities (Article 1) more directly states that "every human being has a fundamental right of access to physical education and sport ... [and the] ... freedom to develop physical, intellectual and moral powers through physical education and sport must be guaranteed both within the educational system and in other aspects of social life." ${ }^{.44}$

On the international stage, there has been judicial recognition of this question in the landmark case of Pistorius v. $I A A F,{ }^{45}$ where the plaintiff, South African track and field runner Oscar Pistorius, argued that it would be discriminatory not to allow him to compete against "able-bodied" competition with prosthetic legs. The International Association of Athletics Federation (IAAF) banned Pistorius from the 2008 Beijing Summer Olympics, finding that the use of prosthetic legs would give him a competitive advantage over "able-bodied" athletes. Pistorius argued that while the prosthetics made him no better than the "able-bodied" athletes it potentially put him at a disadvantage if the conditions were wet or windy. Ultimately the Court of Arbitration for Sport granted him the right to compete in the Olympics, upholding a lower court's decision overturning the original IAAF ban. ${ }^{46}$

While this case was largely centered around what constitutes a level playing field, Pistorius's successful fight for the right to compete in the regular Olympics is an important statement for those arguing for a "right to play" sport. It can be argued that implicit in the rights of disabled persons to enjoy the same access to sport and recreation as able-bodied persons is recognition of a normative right to access sport. ${ }^{47}$ The refugee analog to this case would be the argument that if a disabled person has a recognizable right to access the benefits of "able-bodied" sport, then a refugee should enjoy the same right to access to the benefits of sport.

\section{IOC Refugee Team}

A notable step in the direction to recognize this specific right of refugees to access sport was the formation of the first Refugee Olympic Team during the 2016 Rio Summer Olympics. The International Olympic Committee (IOC) created a fund of \$2 million (USD) to pay for the training of any athletes deemed to meet the

\footnotetext{
42 http://www.unhcr.org/513f37bb9.pdf

43 https://www.cidh.oas.org/basicos/english/basic3.american\%20convention.html

44 Id.

45 Pistorius v. IAAF, CAS 2008/A/1480.

46 Id.

${ }^{47}$ Ireland-Piper \& Weinert, 2014: Is There a "Right" to Sport.
} 
Olympic standard for their respective sport. ${ }^{48}$ To qualify, each athlete seeking to participate under this banner was required to have UN-verified refugee status. In creating this team, the IOC is indirectly acknowledging that even refugees have the right to participate in world sport. Indeed, Thomas Bach, president of the IOC, stated at the time that this was meant as a "message of hope to all the refugees in the world." 49

The 10 athletes of the Refugee Olympic team will not be the last, as the IOC is planning another refugee team for the 2020 Tokyo Summer Olympics that will be trained through a fund that will distribute grants to National Olympic Committees for "athlete development" of refugees that have resettled in their countries. ${ }^{50}$ This "athlete development" fund to ensure that countries hosting refugees have the funds to train Olympians is another step forward toward the implicit right for refugees to have access to sport.

\section{Overview of Legal Issues Surrounding Obtaining Permission and Working in a Refugee Camp}

As previously discussed, whether there is the legal right to sport features prominently in the corpus of international legal instruments. While this question is discussed and strategized at the global level, there are many legal questions that operate simultaneously at the local level in order to implement a sports program for refugees.

These granular questions need to be considered for any type of program, including sports programs. The first question-when to enter a particular crisisreflects a delicate balancing of purpose and goals that has many potential legal consequences. Once the decision has been made to enter a crisis, each country and situation has different permitting procedures. Once in the camp, groups must adhere to strict international reporting standards and safety practices.

The initial decision when entering a crisis involves a program's "theory of change." Depending on the organization's theory of change, it will either be a first responder that parachutes in and provides disaster relief or have a longer-term goal that targets a longer-term solution. In the sports context, different aid groups are positioned differently to respond to varying levels of crises, from disaster relief to long-term protracted refugee situations. For example, the Rohingya refugees flooded into the border area of Cox Bazar, Bangladesh, in such numbers that the "camp" was set up so haphazardly that there were no spaces for youth to be outdoors safely. ${ }^{51}$ As a result, first responder humanitarian aid groups are

\footnotetext{
48 IOC launches Olympic Refuge Foundation in its commitment to support refugees, September 15, 2017, https://www.olympic.org/news/ioc-launches-olympic-refuge-foundation-in-its-commitment-to-support-refugees; See also IOC announces emergency two million dollar fund to help refugees, September 4, 2017. https://www.olympic.org/news/ioc-announces-emergency-two-mil$\underline{\text { lion-dollar-fund-to-help-refugees }}$

49 https://www.thenational.ae/sport/refugee-team-forming-for-rio-2016-olympics-we-want-tosend-a-message-of-hope-1.222117\#full

50 Id.

51 Mercy Corps' Response in Bangladesh to the Rohingya Refugee Crisis (March 2018), copy with author. There are approximately 1,000,000 refugees, half of which are youth.
} 
working with the Bangladeshi government to build emergency sports and community facilities in the Cox Bazar that allow youth, especially girls, to socialize safe from predation and potential injury. ${ }^{52}$ On the other end of the spectrum, a protracted refugee environment such as the Dadaab Refugee camp in Kenya is host to specialized sports organizations such as Right to Play, which enters into a more stable environment with a stable population of refugees.

Regardless of the aid group's role or goals in the relief effort, all groups adhere to the internationally accepted standards set forth by Sphere, which was established in 1997 as a voluntary initiative that brings together hundreds of aid organizations, non-governmental organizations (NGOs), and donor institutions to establish a minimum standard of operation for humanitarian actors in disaster response. Humanitarian Charter and Minimum Standards in Humanitarian Response was formalized by the Sphere groups in 2004 and it acts as an unofficial international rulebook for aid groups acting both in disaster and conflict situations. Sphere is based on two core beliefs: (1) that those affected by disaster or conflict have a right to life with dignity, and therefore, a right to assistance; and (2) that all possible steps should be taken to alleviate human suffering arising out of disaster or conflict. ${ }^{53}$

With regards to sports programming, Sphere recently added to the health chapter of its handbook that included mandates to improve mental and social health during humanitarian assistance; sports and development organizations have been using this standard as applicable reporting guidelines. ${ }^{54}$

Once an organization has incorporated Sphere's core beliefs into the strategies and programming planning, the formal permitting process takes many forms. ${ }^{55}$ The legal process to become operational varies depending on the need on the ground. In some instances where there has been a natural disaster, the host government issues a call for humanitarian groups to enter the country and the process can be very fast. ${ }^{56}$ For example, in instances where there is an influx of refugees into a host country, the process may take 1-2 months while the host country quickly attempts to accommodate large numbers of newly arrived groups seeking basic needs. A host country's attitude towards refugees plays a large role in the permitting process. A country like Afghanistan, whose main income is development aid, will permit much more access than a country in Europe that sees NGOs as a pull-factor for more refugees. ${ }^{57}$

\footnotetext{
52 Id.

53 The Sphere Handbook: Humanitarian Charter and Minimum Standards in Humanitarian Response (2011).

54 Interview with Mercy Corps Director of Strategy.

55 The legal processes varies widely depending on host country and all the differences in permitting is beyond the scope of this article.

56 Interview with Mercy Corps Director of Strategy.

${ }_{57}$ https://thediplomat.com/2016/05/afghanistans-addiction-to-foreign-aid/ ("Because they are so dependent on foreign aid, politicians in Afghanistan spend much of their time courting and catering to international donors, rather than to their constituents. Donors, not citizens, determine the future direction of the country, as the conditionality gives donors the control over the use and direction of their funds.")
} 
Whether a government is welcoming or hostile, the legal requirements aid organizations must meet are generally standard across all countries. Generally, government requirements are the same-requiring establishment of a legal representative in the country (whether it is a formal non-profit entity or a legal agent), previous years' financial audits, forecasted budget, size of projected expatriate workforce, identity of board members, governance structure, and strategy for the crisis. Once permitting is complete, aid organizations operating in the camp are subject to the laws of the host country.

Host countries govern refugee camps using varying approaches. Some countries deploy their enforcement agencies to a larger degree than others. Bangladesh, in dealing with the Rohingya refugees from Myanmar, places local law enforcement inside the camp, while Greece uses its domestic police force to guard the refugee camps where the refugees' movements are tightly restricted. On the other end of the spectrum, Uganda has given refugees the right to employment and access to asylum procedures.

Legal issues are many and while there are universally accepted operating standards outlined by Sphere for implementers when they arrive in-country, there is no universally accepted process for applying for a permit to enter into a host country. Each host country regulates entry and camp governance differently. Jordan, the host-country for Zaatari Refugee Camp and the KickStart Joy soccer program, has been commended for opening its doors to millions of Syrian refugees, but at the same time the Jordanian government has struggled to cope with the influx of refugees into the local economy. The tension between welcoming refugees from a neighboring country and also protecting its own citizens is evident in both its governmental policies toward refugees as well as the daily lives of refugees within Jordan's borders.

\section{KickStart Joy Soccer Program in Za'atari Refugee Camp}

To see how the challenges facing refugee youth and those who use sport to address them merge with each other, it is helpful to look at the Catalyst Foundation for Universal Education's 2017 KickStart Joy Soccer Program in the 80,000 person Za'atari Refugee Camp in Jordan. The program was a three-day training camp at the end of August 2017 that brought four former professional Major League Soccer (MLS) players to Zaatari Refugee Camp outside of Amman, Jordan. The MLS players ran soccer programs for youth in three age groups of boys and girls: Under 12, Under 14, and Under 18.

Numbers of youth in and out of formal education are difficult to obtain, but even those youth that were enrolled in formal education attend school only for half of what would be a regular school day. Cultural norms dictate that girls attend school in the morning and boys attend in the afternoon. As a result, much of the day remains unstructured with large numbers of unengaged youth. This was particularly a problem for the girls in the camp because the general sentiment is that it isn't safe for the girls to play unsupervised in the roads and alleys of the camp, so the alternative for them is to remain indoors. Programs like KickStart Joy that come into the camp that provide structured activity also provide an antidote to 
the concerns about safety and vulnerability. These are the driving forces behind the mix of international conventions and charters discussed in earlier sections.

The partnerships involved in KickStart Joy also reflect the directives in international instruments. The training facility, a brand-new regulation-size turf soccer field, is a collaboration between the social responsibility arm of the Union of European Football Associations (UEFA), one of the largest sporting organizations in the world, and the Asian Football Development Program, which is the Prince Ali bin Hussein of Jordan's foundation. ${ }^{58}$ KickStart Joy itself is a partnership between former professional athletes, professional sports teams, and the Catalyst Foundation, a US 501(c)(3) organization. In this instance, combining corporate social responsibility, private foundations, and individuals allowed a few actors to leverage approximately $\$ 15,000$ to help 600 refugee youth.

Each step during the planning and execution of KickStart Joy displays the delicate balance between host country concerns and humanitarian relief. At least six weeks prior to the program, all participants were required to submit identification to the Jordanian ministry of security for background checks and entry passes into the camp. Upon arrival, the Jordanian police stand guard around a large fenced in enclosure where there is one entry point into and out of the camp. There, the guards collected all passports and after a lengthy wait, the program participants were permitted entry.

Once inside the camp, the normal rhythms of everyday life hum along beside security vehicles that chaperone the KickStart Joy program into and out of the training facility. Any movement to other parts of the camp outside the training facility required at least one day's notice to the Jordanian ministry of security, and when the entire staff of program coaches wanted to see the main part of the camp, a Jordanian police car escorted them. But it wasn't only the lack of physical access to the camp that was challenging, it was also virtual as well since there is no wireless Internet service in the camp. It is common to see groups of youth around the camp surrounding official aid buildings trying to get access to their Internet service, but keeping Wi-Fi out of the camp is one way for the security ministry to limit risk of unrest.

The tension between security concerns and providing a sense of normalcy in an on-going refugee situation was constantly present, even when trying to provide the soccer program with enough supplies, such as water and food. Water and food had to be purchased inside the camp due to difficulties in getting large bulk items into the camp. It turned out that only shop owners with special permits are allowed to leave the camp to restock inventory for their stores. The ban on people leaving the camp also applied to those seeking employment or educational opportunities outside the camp. For example, the Syrian soccer coaches expressed frustration that even though they had the time and qualifications to become certified coaches, they were not permitted to leave the camp for the required training.

KickStart Joy was a small sports program in a complex situation that brought out all the competing interests involved in using sport for development programming in refugee settings. Among the competing interests are the needs of the

\footnotetext{
58 January 2017 UEFA Foundation for Children partnered with the Prince Ali Foundation, Jordanian Football Association, Norwegian Football Federation, and Lays.
} 
refugee youth, humanitarian aid groups, and civil society, operating parallel to the interests of the host nation's security and economic concerns toward its own citizens.

\section{Conclusion}

The international community has long believed in the power of sport's role in humanitarian development. From this belief has arisen many international conventions and charters that form the framework for sports and development. Much of this framework emphasizes the need for partnerships between international sporting organizations, governmental organizations, and the private sector.

The KickStart Joy program is the type of international public-private sports partnership envisioned in UN charters and resolutions. It also provides a close-up look at the type of actors involved in this partnership model, as well as how these partnerships can have an impact in a humanitarian crisis. Lastly, we can see through this program how these projects operate within the extensive body of international refugee laws and conventions both on a global level and a country-state level. 